\title{
Kierkegaard antimoderno, ou para uma tipologia (alternativa) da posição sociopolítica kierkegaardiana
}

Kierkegaard antimodern, or towards an alternative typology for
the kierkegaardian sociopolitical position

Gabriel Guedes Rossatti

gabrielrossatti@gmail.com

(Universidade Federal de Santa Catarina, Florianópolis, Brasil)

\begin{abstract}
Resumo: Kierkegaard, não obstante ser geralmente reconhecido como um dos mais importantes pensadores do século XIX, ainda hoje sofre de interpretações muitas vezes distorcidas, tanto é que seu pensamento sociopolítico, mais especificamente, parece padecer bastante nas mãos de seus intérpretes, os quais muitas vezes o têm como conservador, quando não como reacionário. Neste sentido, pretendo neste artigo tanto reavaliar precisamente a posição sociopolítica de Kierkegaard quanto explicitar diferentes topoi ou temas presentes na produção kierkegaardiana, sendo que ambas estas coisas serão feitas a partir de uma chave de leitura bastante específica, a saber, o conceito de "antimoderno" tal qual trabalhado por Compagnon.
\end{abstract}

Palavras-chave: Kierkegaard; modernidade; antimodernos; moralistas; democracia.

Abstract: Kierkegaard, notwithstanding his reputation as a major nineteenth century thinker, up to this day suffers in the hands of his interpreters, particularly the ones interested in his sociopolitical thought. Indeed, many of them still seem to cling to the view according to which he would have been a conservative, if not a downright reactionary writer. In this sense, taking as a cue the label "antimodern" as developed by Compagnon, I intend to both discern different topoi in his production, as well as more fundamentally propose a different label for his sociopolitical position, viz, antimodern.

Keywords: Kierkegaard; modernity; antimoderns; moralists; democracy.

DOI: http://dx.doi.org/10.11606/issn.2318-9800.v20i1p163-178

"Allez, allez, je les connais bien tous les principes subversifs de vos novateurs rétrogrades, suivant la belle expression de M. Jouy. Est-ce de M. de Jouy, la belle expression?" Théophile Gautier. Les Jeunes-France, 1833.

\footnotetext{
* Devo agradecer a Thiago Faria, doutor pela PUC-RJ, pelos apontamentos feitos seguintes a uma leitura cuidadosa deste texto. Vale também explicitar que este trabalho foi originalmente apresentado no congresso "Kierkegaard: 200 anos depois", ocorrido em maio de 2013, na Unisinos, RS.
} 


\section{Introdução}

Se o ano de 2013 foi, no que diz respeito aos assim chamados "estudos kierkegaardianos", marcado por ter sido o ano de comemoração do bicentenário de nascimento do múltiplo pensador dinamarquês Søren Aabye Kierkegaard (1813-1855) e no que, para mim, tais comemorações de fato exigem de seus leitores e intérpretes abordagens diferenciadas, mais amplas, transversais, as quais permitam traçar um balanço da obra em seus termos mais gerais, então visarei aqui uma chave hermenêutica que ajude a decifrar os sentidos mais profundos da produção kierkegaardiana; mais exatamente, viso aqui sua produção em sua totalidade sob seus aspectos sociopolíticos. Vale, neste sentido, rapidamente apontar que esta teve seu início no insípido artigo de jornal publicado em 1834 sobre a emancipação feminina e no qual se percebe um jovem Kierkegaard ainda demasiado influenciado pelo vulto de Heiberg e por tudo o que este significava - noção de cultura aristocrática [Bildung], elitismo, etc. - e que teve por fim os praticamente niilistas artigos de jornal publicados em 1855. Assim, viso uma produção que se estende por cerca de vinte anos (1834-1855), não obstante suas intermitências, seus recuos, silêncios e hesitações, enfim, falo de uma produção descomunal que teve como suportes tanto a produção de cartas - estas, infelizmente em número reduzidíssimo para os padrões da época -, de diários ou anotações privadas (extrema, exageradamente volumosos), assim como a produção no formato de livros e de artigos de jornal, sem mencionar a publicação própria de um jornal, intitulado $O$ Momento, o que a configura, neste sentido, como uma típica produção do século XIX, por conta mesmo da diversidade de gêneros que tais suportes implicam. Mas, voltando por fim à minha proposta original, lanço aqui como chave hermenêutica a ser desenvolvida neste artigo o conceito de "antimoderno", mas, note-se bem, exatamente tal qual desenvolvido pelo estudioso Antoine Compagnon em sua obra de título Os antimodernos: de Joseph de Maistre a Roland Barthes ${ }^{1} \mathrm{e}$ que tem como objeto uma muito específica, senão singular tradição francesa de pensamento aparentemente conservadora em termos políticos. Resumindo, pois, avançarei a tese de que tal conceito de "antimoderno" serve perfeitamente, tal qual uma luva, dir-se-ia, à figura de Kierkegaard e, consequentemente, à sua produção, e é por isso que agora pretendo retomar as análises de Compagnon, para depois aplicar tal conceito à produção kierkegaardiana. ${ }^{2}$

1 Cf. COMPAGNON, A. Les antimodernes: de Joseph de Maistre à Roland Barthes. Paris: Gallimard, 2005. Vale notar que há tradução para o português da mesma; cf. COMPAGNON, A. Os Antimodernos. Tradução de L. T. Brandini. Belo Horizonte: Ed. UFMG, 2011.

2 Vale já apontar que, tanto por motivo de facilidade quanto por precisão acadêmica, todas as citações da obra de Kierkegaard serão dadas de acordo com o padrão estabelecido nos estudos internacionais a partir da última edição dinamarquesa, a saber, a Søren Kierkegaards Skrifter, editada por Niels Jørgen Cappelørn et al., Copenhague: Gads Forlag, 1997-2013 (55 volumes). Assim, SKS 16, 49 remete à obra de título (em português) "Ponto de vista explicativo acerca de minha atividade como escritor", p. 49. Mencionar cada título de maneira avulsa (sendo que cito obras de gêneros bastante 


\section{Compagnon e a tradição dos "antimodernos"}

De acordo com Compagnon, "antimodernos" são aqueles intelectuais ou escritores (sendo estas categorias demasiadamente equívocas, diga-se de passagem) fundamentalmente ambivalentes em relação à chegada ou aparição da "modernidade". ${ }^{3}$ Mais especificamente, porém, para Compagnon os "antimodernos" seriam aqueles teóricos em conflito com determinadas premissas do projeto moderno, mas, note-se bem, não com absolutamente todas. Em outras palavras, os antimodernos seriam aqueles pensadores, autores ou intelectuais possuidores de uma teoria, por mais implícita que fosse, da modernidade e que, a partir disso, terse-iam colocados como pensadores críticos, senão mais exatamente pessimistas, a respeito de alguns dos pilares, quer dizer, de alguns dos temas mais fundamentais do projeto mesmo da modernidade. Mais vale aqui citar o que o próprio Compagnon entende por seu conceito de "antimodernos":

Quem são os antimodernos? (...) Não todos os campeões do statu [sic] quo, os conservadores e reacionários de toda espécie, não todos os atrabiliários e desenganados de seu tempo, os imobilistas e os ultracistas, os resmungões e os reclamões, mas os modernos em desacordo com os Tempos modernos, o modernismo ou a modernidade, ou os modernos que o foram relutantemente, modernos divididos [déchirés] ou ainda modernos intempestivos. (...) Baudelaire é o seu protótipo, sua modernidade - ele inventou a noção - sendo inseparável de sua resistência ao "mundo moderno". ${ }^{4}(\ldots)$ [Em suma,] Não poder-se-ia melhor definir o antimoderno como moderno, preso ao movimento da história mas incapaz de abrir mão [faire son deuil] do passado. ${ }^{5}$

Percebe-se, pois, que os antimodernos são adversários modernos da modernidade - "os antimodernos não são não importa quais adversários do moderno, mas mais os pensadores do moderno, seus teóricos" - ou seja, um tipo

diversos, i.e. cartas, anotações privadas, obras propriamente ditas, e de períodos diversos etc.) seria problemático na medida em que os títulos não apenas viriam em dinamarquês como, mais especificamente, os cadernos de anotação de Kierkegaard se mostram particularmente difíceis (por excesso de siglas) de serem citados por extenso; não obstante, no que diz respeito às obras mais importantes de Kierkegaard e, na medida em que existirem traduções para o português, tentarei mencionar, geralmente no corpo do texto, pelo menos seus títulos, de forma que os (as) leitores(as) possam minimamente ter noção da obra citada.

3 Vale mencionar que o próprio Compagnon não se dá o trabalho nessa sua obra de explicitar o que entende por "modernidade". Já eu gosto de pensá-la muito a partir de Ortega y Gasset, para o qual o "novo mundo" da modernidade - vale salientar que ele já utilizava a expressão - seria composto a partir da "democracia liberal, [d]a experimentação científica e [d]o industrialismo. Nenhum destes princípios foi inventado pelo século XIX, senão que procedem dos dois séculos anteriores. A honra do século XIX não consiste em sua invenção, e sim em sua implementação" (ORTEGA Y GASSET, J. La Rebelión de las Masas. In: Obras Completas, tomo IV (1926-1931). Madrid: Taurus, 2005, pp. 406407).

4 COMPAGNON, A. Les antimodernes: de Joseph de Maistre à Roland Barthes, pp. 7-8.

5 Idem, p. 13.

6 Idem, p. 24. 
muito específico de resistência fundada em certos preceitos modernos - sendo o mais fundamental deles, o de crítica iluminista ${ }^{7}$ - que são voltados contra a própria modernidade (enquanto constructo teórico) precisamente com o intuito de criticála; em suma, como diz Compagnon uma vez mais, os antimodernos são os "críticos modernos da modernidade". 8 Em outros termos, os antimodernos são aqueles pensadores, escritores, etc. que, por um lado, se encontram em embate constante com a modernidade, enquanto que, por outro lado, a utilizam como suporte, isto é, como condição para o próprio pensamento, invariavelmente crítico ou polêmico, chegando mesmo - segundo um padrão mais ou menos recorrente, nos finais das carreiras destes estrangeiros situados em meio às suas próprias pátrias - à, como será visto adiante, imprecação destemperada, entendendo-se por esta a agudização histérica do discurso desenvolvido ao longo de suas carreiras. Neste sentido, os antimodernos são verdadeiros "franco-atiradores", cuja situação ideológica é das mais complicadas por conta mesmo do caráter necessariamente ambivalente de suas relações para com a modernidade:

Há entre os antimodernos uma fissura e uma indisciplina inalienáveis que os torna o contrário dos centristas, pois a direita lhes concebe de esquerda e a esquerda de direita. Fora de lugar, eles perdem nos dois planos, antes de transformar sua perda em ganho. [...] Entre as vanguardas [avant-gardes] e as retaguardas [arrièregardes], à retaguarda da vanguarda ou à vanguarda da retaguarda, os antimodernos, reivindicando um direito de inventário, fazendo uso do ceticismo e da liberdade, ocupam uma posição aparentemente desconfortável da qual, contudo, tiram uma vantagem certa. [...] Morcegos, os antimodernos convertem uma marginalidade política e um handicap ideológico em trunfo estético. Há neles uma incoerência irredutível que lhes dá sua força. ${ }^{10}$

Com efeito, Compagnon utiliza uma "palavrinha mágica" em meio a estas considerações que, ainda que não citada literalmente por mim na passagem acima, fornece a chave mais profunda em termos de história das ideias para a devida compreensão deste "fio"11 de pensamento que atravessa não apenas a modernidade, mas mais especificamente a modernidade muito mais longa que se pode conceber desde os gregos; refiro-me, em suma, à noção de atopia, ${ }^{12}$ a qual, por sua vez, remete

7 Cf. KOSELLECK, R. Crítica e crise: uma contribuição à patogênese do mundo burguês. Tradução de Luciana V.-B. Castelo-Branco. Rio de Janeiro: UERJ; Contraponto, 1999.

8 COMPAGNON, A. Les antimodernes: de Joseph de Maistre à Roland Barthes, p. 441.

9 Idem, p. 444.

10 Idem, pp. 446-447. Ou, como coloca outro estudioso, ainda que utilizando uma outra etiqueta para os intelectuais que analisa (e que poderiam ser denominados de "antimodernos" sem muitos problemas), "Em análise final os liberais aristocráticos eram partidários da modernidade: eles próprios eram modernos" (KAHAN, A. S. Aristocratic liberalism: the social and political thought of Jacob Burkhardt, John Stuart Mill, and Alexis de Tocqueville. New Brunswick, NJ: Transaction Publishers, 2001, p. 32).

11 COMPAGNON, A. Les antimodernes: de Joseph de Maistre à Roland Barthes, p. 14.

12 Cf. Idem, p. 447. Vale explicitar que Compagnon não investe neste viés de interpretação, 
a Sócrates e sua inclassificável posição em relação aos seus contemporâneos, tema este, aliás, mais do que presente na obra de Kierkegaard. ${ }^{13}$ Assim, os antimodernos são no fundo os herdeiros tardios de ninguém mais ninguém menos do que Sócrates, o que significa que eles fazem parte de toda uma tradição de idiotas, ou seja, de polêmicos sujeitos privados que decidem fazer da ironia, ${ }^{14}$ muitas vezes, o seu meio principal ou favorito de crítica, sendo esta, aliás, uma das explicações possíveis para sua fundamental incompreensibilidade. Isto, por sua vez, me leva a dizer que os "antimodernos" são - parafraseando o título do ensaio de Sartre a respeito de um de seus maiores representantes, a saber, Flaubert - os idiotas da família, os bizarros, portanto, os singulares, aqueles que em grego, tal qual seu "pai primevo", Sócrates,

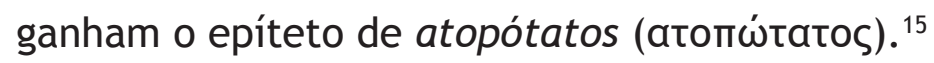

Contudo, para além de uma tipologia diferente acerca desta longínqua tradição de pensamento, Compagnon efetua uma síntese do pensamento dos atopótatos na modernidade francesa de meados do XIX a meados do XX, chegando assim a seis topoi recorrentes nessa linhagem, os quais, como argumentarei, encontram-se claramente presentes na produção kierkegaardiana, convertendo-se mesmo em verdadeiros pilares da mesma; tais temas são fundamentalmente e, tais quais denominados por Compagnon: ${ }^{16}$ I) a figura histórica ou política da contrarrevolução; II) a figura filosófica do anti-iluminismo; III) a figura existencial do pessimismo; IV) a noção deveras fundamental, no sentido etimológico mesmo do termo, de pecado original; V) a figura estética - e, de fato, deve-se ter sempre em mente o caráter em boa medida estético desta tradição, especificamente na modernidade - do sublime; VI) e, por fim, um dos aspectos menos investigados da produção kierkegaardiana, a saber, a vituperação, isto é, a crítica ideológica desenvolvida de maneira aberrante, agressiva, histérica ou mesmo apocalíptica.

\section{Kierkegaard como “antimoderno”}

Esboçado este quadro de referências, volto-me agora à obra de Kierkegaard, de

mencionando, portanto, não apenas Sócrates mas seus herdeiros, os moralistas, apenas en passant.

13 Pois como ele mesmo explicitaria em um de seus escritos literalmente terminais: “a única analogia que tenho diante de mim é Sócrates; minha tarefa é uma tarefa socrática” (SKS 13, 405).

14 Cf. COMPAGNON, A. Les antimodernes: de Joseph de Maistre à Roland Barthes, p. 448.

15 Cf. SKS 16, 49. Ou como bem coloca a questão P. Hadot, “A palavra significa etimologicamente 'fora de lugar', portanto estranho, extravagante, absurdo, inclassificável, déroutant [sic]” (HADOT, P. La figure de Socrate. In: HADOT, P. Exercices spirituels et philosophe antique. Paris: Albin Michel, 2002, p. 120; sobre este tema ver também outro ensaio presente na mesma obra pp. 267ss.). Com relação a uma leitura de Kierkegaard precisamente como atopótatos, vd. VERGOTE, H.-B. Sens et répétition. Essai sur l'ironie kierkegaardienne, t. I \& II. Paris: Cerf/Orante, 1982; por fim, com relação ao topos eminentemente socrático do “idiota”, cf. LAFOND, J. La Rochefoucauld: le moraliste et l'Idiot. In: LAFOND, J. L'homme et son image. Morales et littérature de Montaige à Mandeville. Paris: Honoré Champion, 1996. pp. 305-26.

16 Cf. COMPAGNON, A. Les antimodernes: de Joseph de Maistre à Roland Barthes, p. 17. 
forma a aplicá-lo a esta. Neste sentido, o primeiro topos recorrente no pensamento dos antimodernos, como o próprio nome já o indica, diz respeito à sua colocação diante da Revolução Francesa, mãe, ou melhor, como dizia Burke, "a maternidade de revoluções futuras", ${ }^{17}$ o que de fato acabou por se revelar verdadeiro, uma vez que ela abriu o precedente para todas as revoluções políticas ocorridas no século XIX e para além deste. Mais especificamente, Compagnon reconhece no interior da figura histórica ou política da contrarrevolução - sendo que não vou retomar aqui suas distinções bastante escolásticas entre antimodernos e contramodernos, assim como entre contrarrevolução e antirevolução ${ }^{18}$ - três características mais particulares, a saber, a) o fato de todo contrarrevolucionário ser um emigrado, no sentido de ser um estrangeiro dentro de sua própria pátria; ${ }^{19}$ b) o fato da contrarrevolução replicar à sua antítese em uma dialética que as liga irremediavelmente, o que configura a modernidade dos antimodernos ${ }^{20}$; e c) o caráter eminentemente teórico de sua resistência à Revolução; pois diferentemente dos reacionários ou mesmo dos conservadores, os antimodernos geralmente pressupõem ou uma teoria da Revolução, ${ }^{21}$ ou uma teoria (mais geral) da modernidade. ${ }^{22}$ De fato, vale precisar que Compagnon estipula que o antimoderno é "fundamentalmente um emigrado (...) ou um cosmopolita reticente em se identificar com o sentimento nacional"23, o que significa que "todo antimoderno permanecerá um emigrado do interior". ${ }^{24}$ Ora, tais palavras, por sua vez, mais do que remetem à análise adorniana do intérieur como "a imago concreta do "ponto" filosófico de Kierkegaard". ${ }^{25} \mathrm{E}$ ainda que as análises de Adorno a respeito de Kierkegaard devam, de maneira geral, ser tomadas com certa precaução, ${ }^{26}$ permanece o fato de Kierkegaard ter sido mesmo um "emigrado do intérieur", ou seja, um estrangeiro dentro de sua própria pátria na medida em

17 BURKE, E. Reflections on the revolution in France. CLARK, J.C.D (ed.). Stanford, CA: Stanford Univeristy Press, 2001. p. 177.

18 Cf. COMPAGNON, A. Les antimodernes: de Joseph de Maistre à Roland Barthes, pp. 22-24, 28, 114.

19 Cf. Idem, p. 22.

20 Cf. Idem, p. 23.

21 Cf. Idem, ibidem.

22 Cf. ROSSATTI, G.G. O conceito de modernidade nos escritos primeiros de Kierkegaard: uma análise semântico-conceitual. 2012. 205f. Tese (Doutorado). Programa de Pós-Graduação Interdisciplinar em Ciências Humanas, Universidade Federal de Santa Catarina, Florianópolis 2012.

23 COMPAGNON, A. Les antimodernes: de Joseph de Maistre à Roland Barthes, p. 22.

24 Idem, ibidem.

25 ADORNO, T. W. Kierkegaard: construção do estético. Tradução de Alvaro Valls. São Paulo: Ed. UNESP, 2010, p. 107; sobre o tema do 'intérieur kierkegaardiano', cf. pp. 100-112.

26 Vale esclarecer aqui, ainda que não me interesse entrar nesta seara, que se a leitura adorniana de Kierkegaard pode possuir muitos pontos interessantes, de maneira geral têm-se como ponto pacífico dentro do âmbito dos estudos kierkegaardianos que ela é antes e acima de tudo uma leitura problemática, senão em muitos sentidos equivocada; neste sentido, cf. PATTISON, G. 'Poor Paris!'. Kierkegaard's Critique of the Spectacular City. Berlin and New York: Walter de Gruyter, 1999, pp. 14, 47-48. 
que, particularmente após o "caso Corsário"27, quer dizer, de sua descoberta mais aguda da dinâmica igualitária, o que equivale a dizer da dinâmica revolucionária da época como um todo, ele - as cartas o atestam - resolveu se fechar em sua moradia, esperando, como faria nos anos finais, e tal qual o morcego aludido anteriormente, o momento certo de contra-atacar, no caso o pastor Martensen e toda a igreja dinamarquesa. Logo, a primeira figura aludida por Compagnon é claramente visível na produção kierkegaardiana, ganhando sua formulação através do conceito, devido a Adorno, por sua vez, de intérieur. Não obstante, há ainda dentro deste primeiro topos um traço, desta vez estilístico, que Compagnon reconhece particularmente na obra de Joseph de Maistre e que merece nossa atenção, a saber, seu pendor pela utilização de antimetábolas, isto é, pela repetição de uma sequência de palavras em uma ordem reversa a partir de um ponto de simetria ${ }^{28}$, figura retórica esta que representaria o caráter dialético e, neste sentido, ambivalente, senão irônico dos antimodernos, tal qual lapidarmente formulado na seguinte passagem de Joseph de Maistre, na qual ele considera que "o restabelecimento da Monarquia, o que chamam contrarrevolução, não será uma revolução contrária, mas o contrário da revolução."29 Ora, não é que Kierkegaard, 51 anos após a publicação desse texto de Maistre e (ao que tudo indica) sem tomar conhecimento do mesmo, comentando em carta ao jurista Kolderup-Rosenvinge, no seu caso, exatamente as revoluções de 1848, falaria em termos praticamente idênticos, deixando assim claro que não era um reacionário, e sim um "reacionário dialético", isto é, um antimoderno: "Pois não é esta a lei para a confusão nos últimos acontecimentos europeus: as pessoas querem parar [standse] com o auxílio de uma revolução e uma revolução através de uma contrarrevolução; mas o que é uma contrarrevolução senão uma revolução?" ${ }^{30}$ Assim, Kierkegaard não visava uma contrarrevolução, e sim, tal qual Maistre, o contrário da revolução. ${ }^{31}$

O segundo topos sintetizado por Compagnon, a saber, "a figura filosófica da anti-iluminação", diz respeito à suspeição sistemática dos antimodernos frente ao culto da razão, do idealismo e do utopismo próprios da filosofia enciclopedista ou iluminista do século XVIII. ${ }^{32}$ De fato, se ambos Burke e Maistre deploravam, como dizia o primeiro, os "princípios abstratos" dos revolucionários em detrimento do

27 Embora mesmo antes disso ele já dissesse, ainda que através do pseudônimo Vigilius Haufniensis, autor do Conceito de Angústia, que "eu como autor sou um rei sem país" (SKS 4, 313).

28 Vd. COMPAGNON, A. Les antimodernes: de Joseph de Maistre à Roland Barthes, pp. 28 ss.

29 MAISTRE, J. de. Considérations sur la France. In: CEuvres. GLAUDES, P. (ed.). Paris: Robert Laffont, 2007, p. 276.

30 SKS 28, 399.

31 Especificamente sobre a relação da parte de Kierkegaard para com o conceito de "revolução", cf. ROSSATTI, G. G. Revolution. In: Kierkegaard's Concepts, tome V, EMMANUEL, S., MCDONALD, W and STEWART, J (eds.). Aldershot: Ashgate, 2015, pp. 245-253.

32 Cf. COMPAGNON, A. Les antimodernes: de Joseph de Maistre à Roland Barthes, p. 45. 
"curso da natureza", ${ }^{33}$ Kierkegaard, por sua vez, criticaria os liberais dinamarqueses inebriados com a noção de progresso tal qual esta tomou corpo na Dinamarca a partir da revolução de 1830 na França nos seus primeiros escritos jornalísticos. Assim, sua profissão de fé em termos da necessidade de uma postura realista ou pragmática em política pode ser encontrada em diversas passagens desses artigos de polêmica política, ${ }^{34}$ dos quais pinço agora uma citação:

Da mesma forma que um salto para trás é algo equivocado (o que a época como um todo está suficientemente disposta a reconhecer), da mesma maneira um salto para frente é equivocado - ambos porque um desenvolvimento natural [en naturlig Udvikling] não procede através de saltos, e a seriedade da vida irá ironizar tais experimentos [Forsøg], por mais que sejam bem sucedidos no momento. ${ }^{35}$

Ora, se de acordo com Compagnon, o adágio do protesto antimoderno de realismo em política seria algo como a expressão: “Na vida, é necessário...", ${ }^{36}$ então particularmente os primeiríssimos artigos jornalísticos e discursos de Kierkegaard não são nada senão variações acerca desse adágio, como visto nesta passagem citada há pouco, de acentos, aliás, literalmente burkeanos. ${ }^{37}$ Isto significa que a segunda figura dos antimodernos é estreitamente ligada à concepção de progresso dos modernos, a qual é desacreditada, como dito por Kierkegaard na passagem acima, em nome da "seriedade da vida".

Já a terceira figura dos antimodernos, esta de caráter moral ou existencial, ainda que, no pensamento dos antimodernos ela tenha claras conotações teológicas, ${ }^{38}$

33 Cf. BURKE, Reflections on the Revolution in France, pp. 182-185.

34 Não posso senão remeter, novamente, à minha tese de doutorado, na qual abordo mais detalhadamente estes aspectos; cf. ROSSATTI, G. G. O conceito de modernidade nos escritos primeiros de Kierkegaard: uma análise semântico-conceitual, pp. 38-100. Com efeito, um dos principais problemas desses escritos primeiros de Kierkegaard diz respeito ao fato de serem fundamentalmente réplicas aos textos de seus pares, no caso liberais dinamarqueses inseridos em um imenso debate acerca dos rumos que a Dinamarca enquanto coletividade deveria tomar. Neste sentido, fica praticamente impossível dar uma ideia da posição kierkegaardiana se não se levar em conta tais textos aos quais ele responde, coisa que precisamente não tenho como fazer aqui dadas as limitações deste trabalho. Já para uma análise mais geral da interpretação kierkegaardiana da modernidade, cf. ROSSATTI, G. G. The Present Age. In: Kierkegaard's Concepts, tome V. pp. 113120.

35 SKS 27, 198-199, P254 (1835).

36 Vd. COMPAGNON, A. Les antimodernes: de Joseph de Maistre à Roland Barthes, p. 45.

37 Pois como dissera o mesmo: "A ciência de construção de uma comunidade [commonwealth], ou de sua renovação, ou de sua reforma, não é, como toda outra ciência experimental, para ser ensinada à [sic] priori. (...) A ciência do governo, sendo, portanto, tão prática em si mesma, e compreendida [como] visando tais propósitos práticos, assunto este que requer experiência e muito mais experiência do que qualquer pessoa poderia amealhar em toda sua vida, por mais sagaz e observadora que possa ser, pois é com infinita cautela que qualquer homem deve aventurar-se em derrubar [pulling down] um edifício que respondeu em qualquer medida tolerável de épocas aos propósitos comuns da sociedade, ou de construí-lo novamente, sem possuir modelos e padrões de utilidade aprovada ante seus olhos" (BURKE, E. Reflections on the Revolution in France, p. 220).

38 Vd. COMPAGNON, A. Les antimodernes: de Joseph de Maistre à Roland Barthes, p. 67. 
é, como diz uma vez mais Compagnon, o "pessimismo ou qualquer outro nome que se the queira dar: desespero, melancolia, luto, spleen ou 'mal do século'."39 Curiosamente, segundo o mesmo Compagnon, a palavra "pessimismo" aparece como um neologismo no dicionário Littré (1863-1872), o qual a define como "Opinião de pessimistas"; já o artigo “pessimista”, por sua vez, define este como "Aquele que considera tudo errado. Diz-se às vezes daqueles que, em tempos de dissensões políticas, não esperam o que eles consideram como o bem senão do excesso do mal." 40 Ora, como não pensar no refrão que aparece em tantas obras e anotações privadas de Kierkegaard, a saber, mundus vult decipi ("o mundo quer ser enganado") 41 o qual, por sua vez, legitima a estratégia socrática tal qual esclarecida publicamente em o Ponto de vista acerca de minha atividade como autor?. Mais especificamente, na obra intitulada Uma Recensão Literária, de 1846, Kierkegaard chega mesmo a dizer que

o nivelamento é aquilo que o indivíduo egoísta e a geração egoísta concebiam como o mal, mas também aquilo que para o indivíduo, cada um especificamente, se ele assim quiser isso em sinceridade para com Deus, pode se tornar o ponto de partida [Udgangspunkt] para a vida excelsa - para ele será verdadeiramente educativo viver na época do nivelamento. ${ }^{42}$

Como visto, Kierkegaard, como bom antimoderno pessimista que era, raciocina na base de uma dialética "política do pior", ${ }^{43}$ - vale ainda citar a passagem de 0 Ponto de vista, na qual Kierkegaard confessa ter sido sua "opinião de que 'a guerra' foi uma sorte [Lykke] para a Dinamarca"44 -, o que significa dizer que quanto mais nivelamento, quanto mais imanência ou temporalidade, em suma, quanto mais aguda a dinâmica da modernidade, pior por um lado, isto é, para aqueles poucos ainda ligados à noção de "transcendência", enquanto que, por outro lado, esse mesmo excesso de imanência, concebido nesta face precisamente como um examen rigorosum, ${ }^{45}$ somente tenderia a tornar as coisas mais claras, uma vez que exigiria dos indivíduosmassificados a decisão existencial em relação ao cristianismo (ou a si mesmos) tão privilegiada quanto exigida por Kierkegaard ao longo de seus escritos. Isto tudo, por sua vez, sem mencionar o conceito de "desespero", longamente trabalhado em um livro inteiro dedicado a ele, a saber, Doença para a Morte. ${ }^{46}$

\section{Idem, p. 63.}

40 LITTRÉ apud COMPAGNON, A. Les antimodernes: de Joseph de Maistre à Roland Barthes, p. 64.

$41 \mathrm{Ou}$, como diz Compagnon, “Todos os antimodernos são discípulos de La Boétie" (COMPAGNON, A.

Les antimodernes: de Joseph de Maistre à Roland Barthes, p. 31).

42 SKS 8, 84; minha ênfase.

43 Cf. COMPAGNON, A. Les antimodernes: de Joseph de Maistre à Roland Barthes, p. 64. 44 SKS 16, 48.

45 Cf. SKS 8, 84 (Uma Recensão Literária).

46 Cf. SKS 11, 116-220. 
A quarta figura ou topos do pensamento antimoderno também se encontra mais do que presente ao longo da produção kierkegaardiana, sendo, de fato, um de seus conceitos mais importantes ou fundamentais, a saber, a noção de pecado, objeto mais especificamente tanto deO Conceito de Angústia, onde, não obstante, Vigilius Haufniensis reconhece que ele (o pecado) "Propriamente não pertence a nenhuma ciência”, ${ }^{47}$ assim como de Doença para a Morte, onde se encontra a formulação segundo a qual “O pecado é: diante de Deus, ou com a concepção de Deus, em desespero não querer ser a si mesmo, ou em desespero querer ser a si mesmo." 48 vale apontar que aquilo que Compagnon diz a respeito do uso do conceito de pecado original nas obras dos antimodernos franceses, a saber, que se eles, na qualidade de herdeiros da Revolução Francesa, ${ }^{49}$ relacionam esta retrospectivamente àquele, no que passam a conceber a Revolução como a encarnação total e perfeita do mal, pois tal ligação não deixa de se apresentar na mente de Kierkegaard, o qual chega mesmo a dizer, em Uma Recensão Literária, que o “nivelamento propriamente [dito] não é de Deus [Guddommen]". ${ }^{50}$ Neste sentido, vale precisar que se mais fundamentalmente o uso antimoderno da categoria pecado é feito com o intuito de desacreditar a concepção antropológica implícita no projeto da modernidade, na qual a hubris ${ }^{51}$ toma o lugar da humildade e, consequentemente, de toda uma concepção antropoteológica (de cunho holístico) na qual o ser humano é a parte que deve se adequar em termos de sua posição no cosmo, então é com esse intuito mesmo que Kierkegaard faz uso desse conceito, como se vê claramente ao longo de Doença para a Morte, ${ }^{52}$ entre outras obras.

Como quinta figura ou topos aparece, por sua vez, a complexa noção de sublime. Ora, Compagnon liga o fato da Revolução a uma concepção teológica de regeneração tal qual esta se apresenta na mentalidade e, consequentemente, nos escritos dos antimodernos, a qual, por sua vez, pressupõe ou promove uma aliança entre a categoria estética do sublime, retomada, aliás, por Burke no século XVIII, e a concepção sagrada e sublime do castigo, ${ }^{53}$ segundo a qual o conceito de "sacrifício" desempenha um papel fundamental e de acordo com o qual a figura do "carrasco" acaba sendo alçado ao posto de eixo central do funcionamento social. Em outras palavras, o sublime tal qual compreendido por Compagnon tem a ver com ambas a concepção romântica - senão mais especificamente dos chamados, em alemão,

\footnotetext{
47 SKS 4, 323

48 SKS 11, 191.

49 COMPAGNON, A. Les antimodernes: de Joseph de Maistre à Roland Barthes, p. 103.

50 SKS 8, 102.

51 Cf. COMPAGNON, A. Les antimodernes: de Joseph de Maistre à Roland Barthes, p. 90.

52 Cf. SKS 11, 232.

53 COMPAGNON, A. Les antimodernes: de Joseph de Maistre à Roland Barthes, p. 118.
} 
de Schauerromantiker ${ }^{54}$ - de sublime, a qual promove a aliança entre sangue ou sofrimento, por um lado, e o sagrado, por outro, assim como com noções muito semelhantes tais quais desenvolvidas por Joseph de Maistre, notadamente em seus Esclarecimento sobre o sacrifício. ${ }^{55}$ Ora, como não equacionar esta compreensão a Temor e Tremor - cujo título, aliás, reintroduz em plena modernidade dinamarquesa a noção latina de admiratio, equivalente do sublime moderno -, isto sem falar de outros escritos kierkegaardianos diretamente estruturados a partir de categorias como "sacrifício" ou "martírio"? De fato, o que dizer de um título como Possui um ser humano o direito de se deixar matar pela verdade?, cujos subtítulos, apenas para reforçar seu caráter híbrido entre o sublime e o provocativo, são Resquícios - ou mesmo Excrementos [Efterladenskab] ${ }^{56}$ - de um ser humano solitário. Experimento Poético ${ }^{57} \quad$ E o que dizer da terceira parte dos Discursos Cristãos, intitulada Pensamentos que ferem por detrás - para Edificação ${ }^{58} \mathrm{O}$ fato é que existe claramente uma estética do sofrimento sublime que atravessa - dando-lhe assim sua coloração de vermelho-sangue - a produção kierkegaardiana, a qual, por conta dessa sua estética decandentista - outros diriam barroca, por causa precisamente dessa fascinação pelo corpo em chagas - atrairia muitos escritores e mesmo pintores posteriores (neste sentido poder-se-ia pensar em Kafka e, no nosso caso, em Lúcio Cardoso, assim como no pintor norueguês Edward Munch, todos eles confessos leitores de Kierkegaard). Em suma, a categoria do sublime, não obstante o fato de praticamente não aparecer na obra de Kierkegaard nesses termos, ${ }^{59}$ é de fundamental importância em termos da estruturação de sua obra, a qual, como se sabe, deve seu impacto em boa medida ao seu caráter estético.

Por fim, chegamos à última figura dos antimodernos, a saber, a vituperação, ou aquilo que Compagnon denomina muito felizmente de "estilo da veemência". 60 Com efeito, desde as Reflexões sobre a revolução na França, de Burke, obra esta estruturada como uma carta que, levada adiante muito longamente por causa da

54 A definição dada na versão alemã da enciclopédia eletrônica Wikipedia é, neste sentido, exemplar: "Os românticos sombrios [Schwarze Romantik] (também conhecidos como "românticos do arrepio" [Schauerromantik]) formam uma sub-corrente que surgiu no interior do romantismo por volta de finais do século XVIII. (...) [Estes] se destacam através da ênfase em traços melancólicos e irracionais, assim como por se mostrar atraídos pelas formas da loucura humana e pelo "mal", no que se afastam do movimento liderado pela razão do "Iluminismo", [sendo também] uma reação aos terrores da Revolução Francesa” (http://de.wikipedia.org/wiki/Schwarze_Romantik).

55 Cf. MAISTRE, J. Éclaircissement sur les sacrifices. In: CEuvres, pp. 805-839.

56 Sendo esta palavra em dinamarquês essencialmente dúbia, podendo significar os dois termos colocados acima.

57 Cf. SKS 11, 57-93.

58 Cf. SKS 10, 171-252.

59 Cf. PATTISON, G. The sublime, the city and the present age. In: Kierkegaard, religion and the nineteenth-century crisis of culture. Cambridge: Cambridge University Press, 2002, p. 4, n. 2.

60 COMPAGNON, A. Les antimodernes: de Joseph de Maistre à Roland Barthes, p. 137. 
cólera inesgotável de seu autor, acabou por servir como modelo para muito do que se produziu em termos do debate ideológico no século XIX, a tradição de pensamento dos antimodernos desenvolveu uma forma de escrita baseada na noção de vituperação panfletária, sendo este seu suporte por excelência, isto é, artigos de jornal, os quais, por sua vez, apontam para a concisão enquanto valor estético-retórico e, neste sentido, ajudam a promover o surgimento de escritos veementes ou histéricos por conta de sua agressividade delirante e construídos estilisticamente a partir da abundância de antíteses e oxímoros, isso sem contar a estratégia retórica favorita dos antimodernos, a saber, a ironia. Nas palavras de Compagnon: "Espirituosidade, vivacidade, engenhosidade, imprevisto, impertinência, paradoxo: eis aí uma excelente descrição da ironia, típica do antimoderno". ${ }^{61} \mathrm{Ou}$, como diz ainda outro autor: "Há uma tradição retórica da cólera, cujas origens são evidentemente religiosas (...) e que, finalmente, a partir da Revolução, de gênero oratório que era, se tornou um gênero literário (...)[, o] que permitiu então a toda uma categoria de temperamentos liberar seu mau humor". ${ }^{62}$ Ora, como não ver o "último Kierkegaard”, ou seja, o Kierkegaard dos artigos de jornal publicados entre 1854-1855, dentro desta tradição mais específica, promovendo ele mesmo a dissensão a partir de escritos cataclísmicos, patéticos e de títulos-petardos, como diria Baudelaire, ${ }^{63}$ ele mesmo descrito por Walter Benjamin como "provocateur" possuidor de uma "ironia devastadora"?64 Novamente, como não ver nesses artigos verdadeiros panfletos antimodernos feitos com o intuito de causar uma catástrofe? Pois, de fato, esses artigos não são mais pura e simplesmente escritos no sentido usual de belles-lettres, e sim verdadeiras bombas retóricas formadas a partir de muita tristeza, de muito ódio, em suma, de muito ressentimento, todos cuidadosamente amealhados, gota a gota, ao longo dos anos de silêncio ${ }^{65}$ (meados de 1851 a finais de 1854) e cuja intenção era causar a desconstrução - nome mais polido para implosão - da estrutura milenar da lgreja, no caso, dinamarquesa.

\section{Conclusão: Por uma leitura de Kierkegaard como um "moralista da modernidade", ou seja, como "antimoderno" \\ Como espero ter demonstrado, a categoria antimoderno, precisamente tal}

61 Idem, p. 147.

62 KLOSSOWSKI apud COMPAGNON, A. Les antimodernes: de Joseph de Maistre à Roland Barthes, p. 151.

63 "Amo os títulos misteriosos ou os títulos-petardo" (BAUDELAIRE, C. Correspondance I. PICHOIS, C. (ed.). Paris: Gallimard, coll. Bibliothèque de la Pléiade, 1973, p. 378 [a Poulet-Malassis, 07/03/1857]).

64 Cf. BENJAMIN, W. The Paris of the Second Empire in Baudelaire. In: The Writer of Modern Life. JENNINGS, M. W. (eds.). Cambridge, MA and London: The Belknap Press of Harvard University Press, 2006, pp. 48-49.

65 Cf. VERGOTE, H.-B. Sens et répétition. Essai sur l'ironie kierkegaardienne, t. I, pp. 76 ss. 
qual trabalhada por Compagnon, serve como uma luva, ou melhor, como uma chavemestra para se adentrar na produção kierkegaardiana, seja mais particularmente em seus aspectos sociopolíticos, seja em seus aspectos mais gerais mesmo (teológicos, estéticos, psicológicos, etc.). No que diz respeito a esse primeiro aspecto, ou seja, como chave de leitura para a posição sociopolítica de Kierkegaard, vale aqui explicitar que a concebo literalmente como uma resposta ao falso problema da suposta "posição ideológica" do mesmo; ora, entendo que esse seria um falso problema na medida mesmo em que o pensamento de Kierkegaard não pode ser descrito como propriamente dito ideológico, no sentido de se acordar aos matizes políticos tal qual engessados a partir da Revolução Francesa. Em outros termos: pelo fato de Kierkegaard pensar a política a partir de conceitos ou estruturas mentais alheios ao pensamento sociopolítico propriamente dito, quer dizer, pelo fato mais fundamental de ele pensar a política a partir do âmbito teológico, ${ }^{66}$ sua posição não pode nem tem como ser descrita em termos de "direita", "esquerda", ou mais exatamente, "liberais", "conservadores", etc. Em suma, Kierkegaard não foi e nem teve mesmo a pretensão de ser um pensador sociopolítico tal qual um Marx, um Tocqueville, um J. S. Mill, etc.;67 não obstante, na medida em que viveu no século da "revolução democrática", ${ }^{68}$ não havia maneira não apenas para ele, Kierkegaard, mas para qualquer outro tipo de "escritor" ou de "pensador", por mais apolítico que fosse, de se furtar de abordar essa questão - veja-se o caso de Baudelaire, o " antimoderno" paradigmático para Compagnon e que fazia questão de pensar e fazer a estética o mais longe possível da política; não obstante, Baudelaire reflete a política o tempo todo em sua produção. Mas voltando a Kierkegaard, o olhar que ele lança para o âmbito político acaba sendo um olhar de teólogo, algo que, por sua vez, o leva a enxergar ou diagnosticar determinados aspectos seja da democracia moderna, seja da modernidade em seu termos mais amplos, tais quais outros contemporâneos seus, aqueles mais centrados ou fundados no pensamento propriamente dito sociopolítico tais quais Marx, Tocqueville, Proudhon, etc., não conseguiram enxergar.

66 Pois, como diz com muita propriedade um especialista, “[o] único enfoque hermenêutico ao pensamento de Kierkegaard que possa verdadeiramente apreciar sua contribuição à reflexão sobre a sociedade e a política é aquele que se coloca dentro do próprio pensamento de Kierkegaard, levando em consideração o 'ponto de vista' peculiar de sua atividade como escritor - um ponto de vista que ele explicitamente reconheceu como 'religioso'. Daí, o que é interessante em Kierkegaard é que sua posição não é política ou uma filosofia da política, [sendo] apenas uma consideração da política - através de fragmentos e intuições - a partir de um ponto de vista religioso, com uma referência específica às relações entre política e religião" (NICOLETTI, M. Politics and Religion in Kierkegaard's thought: Secularization and the Martyr. In: CONNELL, G. B.; EVANS, C. S. (orgs.). Foundations of Kierkegaard's Vision of Community. Religion, Ethics, and Politics in Kierkegaard. New Jersey and London: Humanities Press 1992, pp. 183-184).

67 Cf. SLøK, J. Da Kierkegaard tav: Fra forfatterskab til kirkestorm. Copenhague: Hans Reitzels Forlag, 1980, p. 51.

68 TOCQUEVILLE, A. de. La Démocratie en Amérique I. In: CEuvres II. JARDIN, A. et. Al (eds.). Paris: Gallimard, 1992, p. 4. 
E se, por sua vez, tal chave de leitura por acaso possa se mostrar como uma categoria algo equívoca ou problemática, isto, como já apontado anteriormente, provém de suas origens mais primitivas, a saber, de Sócrates, assim como dos desdobramentos posteriores de suas ideias no Ocidente, na medida em que houve uma confluência peculiaríssima entre socratismo e cristianismo, a qual, por sua vez, seria mais do que determinante para muita coisa que ocorreria em termos de história das ideias (ou pura e simplesmente em termos de filosofia, mas também de literatura, teologia, psicologia, etc.). Ora, esta tradição também conhecida como a "tradição dos moralistas", ${ }^{69}$ ganhou uma formulação exemplar da parte de um estudioso contemporâneo, o qual fala mesmo, e de maneira particularmente feliz, da "grande tradição agostiniana de socratismo cristão."70 Pois Kierkegaard é um dos herdeiros mais claros, assim como mais diretos, exatamente dessa tradição, ${ }^{71}$ a qual no século XIX se viu forçada a discutir e a problematizar o surgimento, senão o recrudescimento, (da dinâmica) da modernidade. E é este encontro, portanto, entre mentalidade "moralista", de um lado, e "modernidade", do outro, que daria origem ao que Compagnon denomina de "antimodernos". Neste sentido, enquanto antimoderno, o pensamento de Kierkegaard é dividido entre passado e futuro, ou seja, entre valores socrático-cristãos e modernidade, compreendendo-se por esta seu radicalíssimo individualismo, assim como sua forma de crítica impiedosa, praticamente niilista em termos de sua ausência de limites - basta pensar que foi enquanto teólogo que Kierkegaard propôs e promoveu a dissolução do constructo teológico-político, em um primeiro momento, na Dinamarca, para depois radicalizar essa mesma postura, chegando assim a propor a dissolução completa ou total da própria Igreja em seus escritos terminais. Neste sentido, Bruce Kirmmse, um dos

69 Pois como bem aponta um especialista, "O tipo [no sentido de protótipo - GGR] do moralista é, de fato, Sócrates" (VAN DELFT, L. Les moralistes. Une apologie. Paris: Gallimard, 2008, p. 18).

70 LAFOND, J. Préface. In: Moralistes du XVIle Siècle. Éd. J. Lafond. Paris: Robert Laffont, 1992, p. xiv.

71 Vale mencionar o fato de que em obra recentíssima, um especialista, ao abordar precisamente a interpretação kierkegaardiana da modernidade e, consequentemente, seu pensamento sociopolítico, situa ou classifica Kierkegaard nos seguintes termos, na minha opinião bastante inadequados: "Kierkegaard pode ser visto (...) como um praticante de crítica ideológica [ideology critique]. (...) 'Crítica ideológica' é um termo fundamentalmente associado à tradição marxista [, sendo] um caso específico de hermenêutica da suspeição, a qual foi definida como 'a tentativa deliberada de expor os auto-enganos envolvidos no escondimento de nossos motivos reais operatórios em relação a nós mesmos, individual ou coletivamente'” (WESTPHAL, M. Society, Politics, and Modernity. In: LIPPIT, J.; PATTISON, G. (orgs). The Oxford Handbook of Kierkegaard. Oxford: Oxford University Press, 2013, p. 310). Ora, o que chama a atenção na descrição acima é sua inocência, assim como a relativa distorção dos conceitos, pois quem tiver passado os olhos sobre umas duas páginas do "moralista" La Rochefoucauld (1613-1680) sabe que tal "hermenêutica da suspeição" não vem de (ou tem a ver com) Marx e, sim, da escola "socrático-agostiniana", o que quer dizer, da tradição dos "moralistas". Em suma, quando me refiro às distorções dos especialistas - sendo que este é um dos melhores em nível internacional -, tenho em mente este brutal desconhecimento, para retomar mais uma vez a mais do que feliz colocação de Jean Lafond, da "grande tradição agostiniana de socratismo cristão". 
mais competentes leitores sociopolíticos da produção kierkegaardiana, formula a questão nos seguintes termos: “Como lidamos com alguém que é ambos anticlerical e profundamente cristão?"72 Pois é, a questão está em aberto há uns bons duzentos anos e provavelmente - oxalá! - permanecerá assim por outros duzentos, trezentos, quinhentos anos...

\section{Referências}

ADORNO, T. W. Kierkegaard: construção do estético. In: ADORNO, T. W. Kierkegaard: construção do estético. Tradução de Alvaro Valls. São Paulo: Ed. UNESP, 2010, pp. 19-307.

BAUDELAIRE, C. Correspondance I. PICHOIS, C. (ed.). Paris: Gallimard, coll. Bibliothèque de la Pléiade, 1973.

BENJAMIN, W. The Paris of the Second Empire in Baudelaire. In: BENJAMIN, W. The Writer of Modern Life. JENNINGS, M. W. (ed.). Cambridge, MA and London: The Belknap Press of Harvard University Press, 2006, pp. 46-133.

COMPAGNON, A. Les antimodernes: de Joseph de Maistre à Roland Barthes. Paris: Gallimard, 2005.

HADOT, P. La figure de Socrate. In: HADOT, P. Exercices spirituels et philosophie antique. Paris: Albin Michel, 2002, pp. 101-141.

KAHAN, A. S. Aristocratic liberalism: the social and political thought of Jacob Burkhardt, John Stuart Mill, and Alexis de Tocqueville. New Brunswick, NJ: Transaction Publishers, 2001.

KIERKEGAARD, S. Søren Kierkegaards Skrifter. Udgivet af Niels Jørgen Cappelørn et al., København: Gads Forlag, 1997-2013 (55 volumes).

KIRMMSE, B. 'But I am almost never understood...' Or, Who Killed Søren Kierkegaard?. In: PATTISON, G. \& SHAKESPEARE, S. (eds.). Kierkegaard: the self in society. MacMillan Press, 1998, pp. 165-178.

KOSELLECK, R. Crítica e crise: uma contribuição à patogênese do mundo burguês. Tradução de Luciana V.-B. Castelo-Branco. Rio de Janeiro: UERJ; Contraponto, 1999.

LAFOND, J. Préface. In: Moralistes du XVIle Siècle. Éd. J. Lafond. Paris: Robert Laffont, 1992, pp. I-XLIX.

. La Rochefoucauld: le moraliste et l'Idiot. In: LAFOND, J. L'homme et son image. Morales et littérature de Montaige à Mandeville. Paris: Honoré Champion, 1996, pp. 305-26.

MAISTRE, J. de. Considérations sur la France. In: MAISTRE, J. de. CEuvres. GLAUDES, P. (ed.). Paris: Robert Laffont, 2007, pp. 199-289.

Éclaircissement sur les sacrifices. In: MAISTRE, J. de. OEuvres. Glaudes, P. (ed.). Paris: Robert Laffont, 2007, pp. 805-839.

72 KIRMMSE, B. 'But I am almost never understood...' Or, Who Killed Søren Kierkegaard?. In: PATTISON, G. \& SHAKESPEARE, S. (Eds.). Kierkegaard: the self in society. MacMillan Press, 1998, p. 178. 
NICOLETTI, M. Politics and Religion in Kierkegaard's thought: Secularization and the Martyr. In: CONNELL, G. B.; EVANS, C. S. (orgs.). Foundations of Kierkegaard's Vision of Community. Religion, Ethics, and Politics in Kierkegaard. New Jersey and London: Humanities Press, 1992, pp. 183-195.

ORTEGA Y GASSET, J. La Rebelión de las Masas. In: ORTEGA Y GASSET, J. Obras Completas, tomo IV (1926-1931). Madrid: Taurus, 2005, pp. 347-528.

PATTISON, G. 'Poor Paris!'. Kierkegaard's Critique of the Spectacular City. Berlin and New York: Walter de Gruyter, 1999.

The sublime, the city and the present age. In: PATTISON, G. Kierkegaard, religion and the nineteenth-century crisis of culture. Cambridge: Cambridge University Press, 2002, pp. 1-24.

ROSSATTI, G.G. O conceito de modernidade nos escritos primeiros de Kierkegaard: uma análise semântico-conceitual. 2012. 205f. Tese (Doutorado). Programa de Pós-Graduação Interdisciplinar em Ciências Humanas, Universidade Federal de Santa Catarina, Florianópolis 2012.

. The Present Age. In: EMMANUEL, S.; MCDONALD, W. AND STEWART, J. (orgs). Kierkegaard's Concepts, tome V. Aldershot: Ashgate, 2015, pp. 113-120. . Revolution. In: EMMANUEL, S.; MCDONALD, W. AND STEWART, J. (orgs). Kierkegaard's Concepts, tome V. Aldershot: Ashgate, 2015, pp. 245-253.

SLØK, J. Da Kierkegaard tav: Fra forfatterskab til kirkestorm. København: Hans Reitzels Forlag, 1980.

TOCQUEVILLE, A. de. La Démocratie en Amérique I. In: OEuvres II. JARDIN, A. (ed.) et. al. Paris: Gallimard, 1992, pp. 3-506.

VAN DELFT, L. Les moralistes. Une apologie. Paris: Gallimard, 2008.

VERGOTE, H.-B. Sens et répétition. Essai sur l'ironie kierkegaardienne, t. I \& II. Paris: Cerf/Orante, 1982.

WESTPHAL, M. Society, Politics, and Modernity. In: LIPPIT, J.; PATTISON, G. (orgs). The Oxford Handbook of Kierkegaard. Oxford: Oxford University Press, 2013, pp. 310-327. 